\title{
A “CONSTITUCIONALIZAÇÃO” DO TIRANICÍDIO
}

José Adércio Leite Sampaio ${ }^{1 *}$ Luana Mathias Souto ${ }^{2 * *}$

\section{Resumo:}

O presente artigo tem por objetivo analisar a intrínseca relação entre o tiranicídio praticado na Antiguidade, na Idade Média e na Alta Modernidade, e o desenvolvimento de alguns institutos constitucionais como o direito de resistência e o impeachment. Para tanto, utilizouse dos métodos de crítica e abstração; análise e síntese, com apoio em ampla revisão bibliográfica.

Palavras chave: Tirano; Tiranicídio; Estado Constitucional; Direito de resistência; Impeachment.

\section{THE “CONSTITUTIONALISATION” OF TYRANNICIDE}

\begin{abstract}
:
The present article aims to analyze the intrinsic relationship between tyrannicide practiced in Antiquity, the Middle Ages and High Modernity, and the development of some constitutional institutes such as the right of resistance and impeachment. For that, the methods of criticism and abstraction; analysis and synthesis were used, with support in a wide bibliographic review.
\end{abstract}

Keywords: Tyrant; Tyrannicide; Constitutional State; Right of resistance; Impeachment.

\section{INTRODUÇÃO}

Diversos estudos que vão da filosofia à antropologia e sociologia procuram revelar a natureza intrinsecamente social - ou política - do ser humano (ARISTÓTELES, 1997; RUNCIMAN, 2000). Os traços arqueológicos revelam que, desde os primórdios tempos, a humanidade gravitou evolutivamente de bandos a formações sociais mais complexas (DICE, 1955). Quando o ganho de maturidade intelectual e a diferenciação dos papeis permitiram uma discussão teórica mais elaborada, uma questão passou a interpelar algumas mentes: como constituir uma sociedade ideal ou justa. A história registra a existência de variadas

\footnotetext{
1* Doutor em Direito Constitucional. Professor da PUC-MG e ESDHC. Procurador da República. Endereço eletrônico: joseadercio@terra.com.br

2** Mestre em Direito Público pela Pontifícia Universidade Católica de Minas Gerais. Endereço eletrônico: luasouth@gmail.com.
} 
conformações políticas: de regimes aristocráticos, oligárquicos e democráticos até regimes políticos tirânicos. Os estudiosos, todavia, discordavam na hora de identificar aqueles que lhes pareciam mais adequados, valendo-se de critérios tão plurais quanto o clima e a topografia do Estado e a cultura dos povos (TOCQUEVILLE, 1973). Havia, porém, uma conclusão quase sempre presente nessas análises: a tirania era, de todos, o pior (HUNTINGTON, 1965).

Essa nota historiográfica não é menos verdadeira nos dias atuais. Newton Bignotto parece falar pelo coro de vozes quando afirma que "a tirania não é um regime como os outros. Ela é o ideal negativo da vida política" (BIGNOTTO, 1998, p. 131). A reprovação teórica não importa que sua instituição seja peça de museu. Diversos regimes, alguns, inclusive, com auras constitucionais, demonstram elementos, em maior ou menor grau, de resíduos tirânicos. Rejeita-se o nome; mantém-se a prática. O constitucionalismo nasceu como uma aquisição evolutiva contra a tirania e desenvolveu uma série de instrumentos que visaram preveni-la e combatê-la. O curioso é que os vínculos desses instrumentos como barreiras a práticas tirânicas se perderam entre as linhas da bibliografia constitucional e política. O projeto pacificador das Constituições pode ter ajudado a esconder traços das formas violentas de reação aos regimes tirânicos, mas não se pode deixar de notar nas "pegadas históricas" que elas transforam tal reação num processo jurídico e institucionalizado de "matar" o tirano, ainda que sob a forma de uma metáfora ou de um coma induzido que lhe retira o poder. Vários institutos constitucionais estão a revelá-las: o direito de resistência, o impeachment, o recall e, de certa maneira, a própria criação do Tribunal Penal Internacional.

Todos esses institutos têm em comum a destituição do poder daquele considerado como um mau governante, que não atende aos anseios do corpo social e que lhe fere com opressão e violência. Não seria também esses os elementos que levavam as sociedades préconstitucionais a praticar o tiranicídio? Provavelmente, nessas linhas introdutórias, o interlocutor não seja capaz de assimilar o quanto todos eles são semelhantes, filhos do mesmo útero, havendo, por isso, a necessidade de avançar para além desta página inicial.

Assim, primeiramente, a partir da utilização dos métodos empírico e dedutivo e com apoio em ampla revisão bibliográfica, será realizada uma breve exposição sobre o Estado Constitucional, sua origem, pressupostos e principais características. Em seguida, dedica-se à compreensão do que seja uma "constitucionalização" da tirania o que, por sua vez, acarreta a necessidade de análise da relegitimação da morte política, apresentando, assim, os mecanismos por meio dos quais ela se manifesta. Enfim, a partir das ideias expostas, é que se poderá concluir pela confirmação da premissa acima apresentada. 
Por fim, o objetivo do presente estudo é, portanto, de repensar como foram construídas e configuradas as bases jurídico-constitucionais que alicerçam o Estado e a sua relação com o poder político. O momento não pode ser outro, em que, diante dos recentes acontecimentos que marcaram o país nos últimos dois anos, a organização e o funcionamento políticos do Estado brasileiro foram colocados em destaque e dividiram o País.

\section{O ESTADO CONSTITUCIONAL}

Apesar de existir um impulso doutrinário que classifica o Constitucionalismo em Antigo e Moderno, "a ideia de uma constituição formal, no sentido de uma constituição jurídica ou normativa, portanto, como expressão de um poder constituinte formal, encontrou sua afirmação (teórica e prática) apenas a partir do final do século XVIII" (SARLET; MARINONI; MITIDIERO, 2016, p. 41). De forma que, somente ao final da Modernidade e por meio de suas revoluções, tem início os Estados constitucionais, assim, denominados, por encontrarem-se estruturados e organizados de acordo com um texto constitucional, composto de normas consideradas hierarquicamente superiores às demais e fruto de um processo constituinte originário (SAMPAIO, 2013).

O contexto histórico que inspira a criação de Estados constitucionalmente estruturados advém da insatisfação popular frente aos desmandos de uma monarquia absoluta e intervencionista, que muito exigia de seus súditos e pouco fazia em contrapartida. Oprimidos em seus direitos e sobrecarregados em deveres, as classe politicamente menos privilegiadas se organizaram e deflagraram, a partir disso, diversas revoltas com o cunho de reprimir e limitar os contornos do poder político existente à época.

\footnotetext{
O primeiro grande movimento de ruptura ocorreu na Inglaterra. Uma revolução em dois tempos se deu por lá. Uma tipicamente moderna e violenta, a guerra civil; outra, mais transicional e Whig, a Revolução Glorisosa. Na França, as mudanças se fizeram de modo virulento, tanto em seu momento originário quanto com o Terror dos anos seguintes, para assumir formas mais graduais com a reação termidoriana e o 18 de Brumário. Nos Estados Unidos, os movimentos inaugurais de guerra frente ao colonizador inglês se encaminharam, depois, para institucionalização jurídica, por meio, inicialmente, dos Atos Confederados e, enfim, da Constituição (SAMPAIO, 2013, p. 14).
}

Entretanto, dentre esses movimentos revolucionários, aquele que ensejou a criação de uma Constituição escrita e que, por isso, a demarca como "a primeira constituição escrita no sentido moderno do termo" (SARLET, 2016, p. 49-50) foi a Guerra de Independência dos EUA (1775-1783), que culminou não só com a confecção da referida Constituição, mas 
também com a promulgação da Declaração dos Direitos da Virgínia de 1776, inaugurando ali um novo paradigma jurídico e político, no qual as leis passaram a ser produto da vontade popular em prol da construção de um Estado, sob as balizas e limites constitucionais, e não mais como meros atos de governo ou de poder. Assim, substitui-se a obediência ao querer e agir do rei por uma liberdade de viver perante a lei, instituindo-se o Estado de Direito.

Por fim, podem-se destacar como características e/ou fundamentos preliminares de um Estado Constitucional: a subjugação do Estado às leis e, por consequência, a primazia ao texto constitucional; a elevação da soberania popular a condição de força estruturante do Estado; a prefixação de direitos considerados fundamentais, cuja finalidade, a princípio, era de proteger a liberdade, a propriedade e igualdade dos indivíduos frente ao poder estatal; e a separação do poder político em três esferas de atuação que são independentes e harmônicas entre si, com vistas à sua limitação, evitando-se a sua concentração nas mãos de um único indivíduo ou grupo de indivíduos. (SAMPAIO, 2013; SARLET; MARINONI; MITIDIERO, 2016).

\section{A “CONSTITUCIONALIZAÇÃO” DA TIRANIA}

Com a criação de Estados constitucionalmente limitados, ao final da Era Moderna, acreditou-se estar rompendo com o modelo absolutista de governar, que, ao longo de séculos, conviveu com a prática recorrente de abusos perpetrados por reis divinamente legitimados, perpétuos e absolutos. (SAMPAIO, 2013, p. 53³).

Instituindo um poder político atrelado à lei, visava-se construir uma sociedade distante do passado de horrores em que homens poderosos, cujos desejos não conheciam limites e cujas ações estavam respaldadas em um direito divino que impedia seus súditos de qualquer insurgência ou rebelião. A obediência havia de ser estrita, sob pena de incorrerem em dupla sanção: dos homens, pela traição perpetrada; e de Deus, pela desobediência ao governante, por Ele, escolhido. Morreriam com a eternidade do inferno a cravejar seus

\footnotetext{
3 "Remetendo-se às origens (o paraíso perdido) e à sua degeneração (o estado de natureza), a operação constituinte (de o povo dar-se uma Constituição ou firmar um contrato social) fornecia outra oportunidade emancipadora ao homem. O Estado constitucional propunha-se a ser uma nova ordem social e política capaz de promover os potenciais de progresso (redenção) da humanidade. Ou recuperar a oportunidade perdida. Pragmaticamente, a noção de contrato originário mobilizava todo imaginário político, de modo inconsciente, a reconhecer no processo uma espécie de retorno ao mito fundador, e, de modo racional, a estabelecer as bases da nova organização e divisão de tarefas, segundo as ciências e sempre no sentido de negar-se o Antigo Regime e suas injustiças (impiedades)" (SAMPAIO, 2013, p. 53).
} 
destinos anímicos. Um discurso mais que simples, simplório, mas que bastava para dominar as consciências.

A configuração de uma ordem social constitucional com intento entre mecanicista e racional de legitimar o poder em bases populares e, ao mesmo tempo, conter-lhe os excessos, não significava que a legitimação se operasse ope constitutinis. Entre tantas variantes, havia sempre e persistentemente a natureza humana e seus desejos e instintos de dominação e conquista que se projetavam nas práticas políticas como uma possibilidade de subversão ou de manipulação da ordem instituída em seu proveito e deleite.

\begin{abstract}
Afirmar que no século XXI já não existem despotismos nem tiranias seria uma postura ingênua e inexata; tanto mais errada como tampouco é honestamente aceitável designar indistintamente como "ditaduras" a todos os regimes opressivos do planeta, que concorrem em modo alucinante a violar os mais imprescindíveis direitos humanos ${ }^{4}$. (TURCHETTI, 2007, p. 106, tradução nossa).
\end{abstract}

Não é pouco usual na vida política o ímpeto, por aquele que alcança o poder e a glória de estar à frente, liderando seus concidadãos, pela manutenção dessa posição. O poder alicia, seduz, contagia. O que difere um tirano, em sua acepção clássica, de qualquer outro governante é a arma pela qual cada um se utiliza para manter-se no poder. O tirano gregoabsolutista $^{5}$ opera pelo uso irrestrito da violência física. Irrestrito, porque ameaça e mata qualquer um (amigo ou inimigo) que ousar se insurgir contra ele e seu amado poder. (BIGNOTTO, 1998).

Mas há o "tirano moderno", que pode assumir a forma transitória de um potestas factum, mas, não raras vezes, adota o feitio “constitucional”. O primeiro se vale de um poder de fato para impor sua vontade, com requintes de violência e arbítrio, em nada diferenciandose dos antigos. Essa é, porém, uma via transitória de conquista pelo medo e terror até que se estabilize a posição de comando. Nesse instante, avia-se a receita de uma Constituição de aparência (GEDDES, 2003; MAGALONI, 2008; WRIGHT, 2008).

O "tirano constitucional", embora aqui pareça uma contradição em termos, opera-se pelas fórmulas simbólicas e semânticas da gramática constitucional. São aqueles que se valem da proclamação solene de uma Constituição, garantidora formal da separação de poderes e de direitos fundamentais, para manipular sua efetuação, deixando-a válida e reverenciada, mas

\footnotetext{
${ }^{4}$ Afirmar que en el siglo XXI ya no existen despotismos ni tiranías sería una postura ingenua e inexacta; tanto más errada como tampoco es honestamente aceptable designar indistintamente como «dictaduras» a todos los regímenes opresivos del planeta, que concurren en modo alucinante a violar los derechos humanos más imprescriptibles.

${ }^{5}$ Em alusão às formas de tirania conhecida por gregos e romanos na Idade Antiga e pela tirania contumaz em Estados Absolutistas, todas anteriores aos Estados Constitucionais.
} 
inefetiva. Não está ele a ela submetido; mas ela, a ele, é mera serviçal, pretexto e verniz de poder e mando (LOEWENTEIN, 1976, p. 218; BROWN, 2002; HUNTINGTON, 2006; POSNER; YOUNG, 2007).

Ao final da Modernidade e a partir das primeiras Constituições, a tirania passou a representar, além de um governo autoritário, violento, abusivo e degenerado em seus propósitos, também um violador contumaz de direitos fundamentais, ainda que proclamados por uma Constituição que jurou defender. (TURCHETTI, 2007).

Alexis de Tocqueville (1973) já assinalava, em sua obra A democracia na América, quando se dedicou a estudar a sociedade norte-americana em 1835, a modificação do uso da violência pelo governante, naquele Estado, fruto das revoluções do século XVIII e da onda constitucionalizante:

Cadeias e carrascos, eis os instrumentos antigos de que se servia a tirania; mas, atualmente, a civilização aperfeiçoou até o despotismo, que, no entanto, parecia nada mais ter a aprender. Os príncipes tinham, por assim dizer, materializado a violência; as repúblicas democráticas atuais tornaram-na tão intelectual quanto a vontade humana, que almeja sujeitar. No regime absoluto de um só, o despotismo, para chegar à alma, violentava grosseiramente o corpo; e a alma, escapando aos golpes, eleva-se gloriosa acima dele; mas, nas repúblicas democráticas, não é assim que procede a tirania; deixa de lado o corpo e vai direto à alma. O mestre não diz mais: 'Pensarás como eu ou morrerás'; mas diz: 'És livre de não pensar como eu; a vida, os bens, tudo te é assegurado, mas, deste dia em diante, és um estrangeiro entre nós. Os privilégios da cidadania são mantidos, mas tornar-se-ão inúteis; pois se buscas o voto de teus concidadãos, não o darão, se só pedes a estima, farão como se recusassem. Restarás entre os homens, perdendo o direito à humanidade. Quando te aproximares de um semelhante fugirá como de um impuro; e os que crêem em tua inocência também te abandonarão, porque seriam evitados por sua vez. Vai em paz, deixo-te a vida, mas torno-a pior do que a morte' As monarquias absolutas tinham desonrado o despotismo; evitemos que as democracias o reabilitem e que, tornandoo mais pesado para alguns, impeça a maioria de ver seu aspecto odioso e seu caráter envilecedor" (TOCQUEVILLE, 1973, p. 243-244).

A partir desse momento, surge a opressão por meio das leis, do direito e de um aparato jurídico moldado para atender a interesses vis, pois "o tirano não governa necessariamente e o tempo todo se servindo da violência. O que ele nega é a dimensão política da vida em comum" (BIGNOTTO, 2016, p. 234). De forma que o que se deve ter sempre em mente é que a tirania, como regime político, é um dos elementos que compõem a teoria geral da política, "o tirano é, assim, parte integrante de nosso universo coletivo, mesmo sendo seu personagem mais abjeto" (BIGNOTTO, 1998, p. 138).

Os Estados constitucionalmente estruturados, portanto, tem na sua origem e numa finalidade indizível um elemento intrínseco de internalização dessa violência e possibilitador de sua manifestação. Eis o paradoxo: a Constituição nasceu para combater a tirania, mas 
deixou janelas abertas a sua introdução. O constitucionalismo, embora tenha tentado abrandar o domínio, dando-lhe limites, não deixou de possibilitar a violência da própria dominação e a arquitetura de um sistema que acaba gerando diferentes classes, de dominadores e dominados (BOURDIEU, 1986; DERRIDA, 1994; AGAMBEN, 2007).

Essa imanência tirânica atua como substituto funcional à legitimação divina. Os "tiranos constitucionais", esses da sutileza e imanência, mais do que aqueles, há pouco, referidos, de explícito exercício tirânico, carregam traços de insuspeita legalidade, pois se dizem obedientes aos ditames constitucionais/civilizados, enquanto que, com o respaldo e por meio das leis, exercem o domínio e obrigam a sujeição de formais coautores das normas. $\mathrm{Na}$ prática, embora proclamem a vontade popular como fonte e a Constituição como processo de sua manifestação, há sempre poucos que se beneficiam do aparato jurídico-legal, colocando sob sua vontade e jugo os demais (ARENDT, 20076).

Se, de fato, a Constituição não acabou com o fenômeno tirânico, possibilitando que assumisse outras roupagens; trouxe a possibilidade institucionalizada de combatê-lo (CAREY, 2000; ALBERTUS; MENALDO, 2014). O tirano à antiga estava imerso na política; o tirano constitucional está sujeito ao direito, o mesmo que lhe possibilita a existência. (WEINGAST, 1997; MYERSON, 2008).

\title{
4. A MORTE POLÍTICA RELEGITIMADA
}

Não apenas a tirania encontrou maneiras de se inserir no contexto constitucional; a forma de puni-la, o tiranicídio, forjou mecanismos para se manter operante nos modos e processos de um Estado de Direito.

\begin{abstract}
Existe, então, uma definição de tiranicídio "moderno"? Está claro que sim: por tiranicídio entendemos a neutralização da tirania (como todo o sistema ideológico, militar, econômico, religioso, social e tecnológico mediante o qual esta se opera), seja pela expulsão do tirano (seja um só ou um grupo) - pelo exílio voluntário, ou recorrendo a outras penas, in extremis para suprimi-lo fisicamente. O tiranicídio em sua versão "moderna" exige o respeito às exigências de direito internacional, que representa entre outros aspectos excluir a pena de morte. Por meio do qual, a realização do tiranicídio consistem em denunciar ao suposto culpado de tirania (um ou vários) perante um tribunal penal internacional (veja o caso "Milosevic") ${ }^{7}$. (TURCHETTI, 2007, p. 110, tradução nossa).
\end{abstract}

\footnotetext{
${ }^{6}$ Mais precisamente: "as soluções totalitárias podem bem sobreviver à queda dos regimes totalitários na forma de fortes tentações que surgirão sempre que parecer impossível aliviar a miséria política, social ou econômica de um modo digno do homem.”. (ARENDT, 2007, p. 509).

7 ¿Existe, entonces, una definición del tiranicidio "moderno"? Claro está que sí: Por tiranicidio entendemos la neutralización de la tiranía (con todo el sistema ideológico, militar, económico, religioso, social y tecnológico
} 
Assim, a morte política é relegitimada, reconfigurada e inserida no ordenamento jurídico interno e externo. Ainda persiste, como pressuposto de uma vida em sociedade, que o tirano seja vencido e afugentado, retirando-lhe o poder. A diferença, contudo, é que o constitucionalismo, com seu sistema de garantias, não admite que a violência bruta ou a sua expressão mais visível, ainda que institucionalizada, seja usada contra os tiranos. A pena de morte é proibida pela maioria dos países constitucionais ou é admitida para situações excepcionais. A vida é um direito oponível a todos, aos que comandam; mas também aos comandados.

Autores como Michel Foucault (1999), Hannah Arendt (2014) e Giorgio Agamben (2007) consideram que, com a Modernidade, instaurou-se a biopolítica, em que a vida humana foi colocada à prova no jogo político, não se fazendo mais, como os Antigos faziam, a distinção entre zoé (a simples vida dos seres vivos, biologicamente configurada) e a biós (forma de vida política, própria aos cidadãos) ${ }^{8}$.

Contudo, ironicamente, o "tiranicídio constitucional", a forma constitucionalizada de "matar" o tirano, abranda a distinção, pois prefere a sacrificar-lhe a biós. Violenta-se apenas o seu "eu político", em uma noção inversa da biopolítica, enquanto que a sacrificabilidade da zoé permanece para os demais indivíduos.

Mas até mesmo o outro caráter que define a vida do homo sacer, ou seja, a sua
insacrificabilidade nas formas previstas pelo rito ou pela lei reencontra-se
minuciosamente relacionado com a pessoa do soberano. Michael Walzer observou
que, aos olhos dos contemporâneos, a enormidade da ruptura representada pela
decapitação de Luís XVI, a 21 de janeiro de 1793 , não consistia tanto no fato de que
um monarca tivesse sido morto, mas em que ele tivesse sido submetido a processo e
tivesse sido justiçado numa execução de condenação à pena capital (Walzer, 1988,
p. 184-185): Ainda nas constituiçães modernas, um traço secularizado da
insacrificabilidade da vida do soberano sobrevive no princípio segundo o qual o
chefe de Estado não pode ser submetido a um processo judiciário ordinário. Na
constituição americana, por exemplo, o impeachment implica uma sentença especial
do Senado presidido pelo Chief justice, que pode ser pronunciada somente por high
crimes and misdemeanors e cuja consequência é apenas a deposição do ofício, e não
uma pena judicial. Os jacobinos que, em 1792 , durante as discussões na convenção,
queriam que o rei fosse simplesmente morto sem processo, levaram ao extremo,
ainda que provavelmente sem dar-se conta, a fidelidade ao princípio da

mediante el cual ésta opera), ya sea por la expulsión del tirano (bien sea uno solo o un grupo) — por el exilio voluntario, o recurriendo a otras penas, in extremis hasta suprimirlo físicamente. El tiranicidio en su versión «moderna» exige el respeto a las exigencias del derecho internacional, que suponen entre otros excluir la pena de muerte. Por lo cual, la realización del tiranicidio consiste em denunciar al supuesto culpable de tiranía (uno o varios) ante un tribunal penal internacional (véase el caso "Milosevic").

8 "O homem, durante milênios, permaneceu o que era para Aristóteles: um animal vivo e, além disso, capaz de existência política; o homem moderno é um animal, em cuja política, sua vida de ser vivo está em questão.". (FOUCAULT, 1999, p. 134). 
insacrificabilidade da vida sacra, que qualquer um pode matar sem cometer homicídio, mas que não poder ser submetida às formas sancionadas de execução. (AGAMBEN, 2007, p. 109-110, grifo nosso).

O dilema e paradoxo se instalaram com o constitucionalismo, porque o que ensejou os movimentos revolucionários do século $\mathrm{XVIII}^{9}$ foi, justamente, a legitimação de um direito a resistir contra o governo tirânico; mas como se operará o uso desse direito, uma vez estabelecido o Estado de Direito? Como satisfazer esse propósito, de resistir ao tirano, quando a vida é, secularmente, "sagrada" e os ditames constitucionais devem ser respeitados? As respostas encontradas alcançam níveis diferentes de normatização e, por vezes, mais ou menos expostas.

\subsection{Direito de resistência}

O direito de resistência ou direito de rebelião surge com a sociedade civil organizada por meio das teorias do contrato $\operatorname{social}^{10}$, em que se criam obrigações tanto para os governantes, quanto para os governados, de forma que, ao Estado, é conferido o poder de gerir o corpo social, desde que, em contrapartida, seja habilmente capaz de proteger a vida, a liberdade e a propriedade privada. Aos governados, por sua vez, cabe à abdicação de parte do poder para entregá-lo ao governante, além da obediência às leis e observância aos direitos criados.

\footnotetext{
${ }^{9}$ Os textos das Declaração de Independência dos Estados Unidos e das Declarações francesas de 1789 (artigo $2^{\circ}$ ) e 1793 (art. 29) continham expressamente em seus dispositivos o direito de resistência como um direito natural do homem.

${ }^{10}$ Principalmente a desenvolvida por Locke, para quem: "A autodefesa é uma parte da lei da natureza; não pode ser negada à comunidade, nem mesmo contra o próprio rei. Mas não se deve deixar que ela se vingue sobre ele, pois isso não está de acordo com a lei da natureza. Por isso, se o rei demonstrar um sentimento de ódio, não apenas a determinadas pessoas, mas se colocar contra todo o conjunto da comunidade civil, de que ele é o chefe, e, com um mau uso intolerável do poder, cruelmente tiranizar todo o povo ou uma considerável parte dele, neste caso o povo tem o direito de resistir e se defender da injúria. Mas isso deve ser feito com cautela, pois ele só tem o direito de se defender, não de atacar seu príncipe. O povo pode reparar os danos causados, mas não deve, por nenhuma provocação, exceder os limites da reverência e do respeito devidos. Pode rejeitar a presente tentativa, mas não deve vingar violências passadas. Para nós, é natural defender a vida e uma parte do corpo; mas um inferior punir um superior é contra a natureza. O malfeito dirigido ao povo deve ser evitado por ele antes que seja cometido, mas se for cometido, ele não deve se vingar sobre a pessoa do rei, ainda que ele seja o autor da vilania. Eis, então, o privilégio do povo em geral, acima do ódio de qualquer pessoa individualmente: segundo nossos próprios adversários (exceto apenas Buchanan), aquelas pessoas individualmente não têm outro recurso senão a paciência; mas o conjunto do povo pode, com respeito, resistir à tirania intolerável; mas quando ela for apenas moderada, devem suportá-la'.” (LOCKE, n.d, p. 99).
} 
Esse direito surge, justamente, dessa composição de vontades, de forma que, se houver o descumprimento dos termos acordados por qualquer uma das partes, caberá à outra parte utilizar dos meios adequados para compeli-la a cumprir. Assim, da mesma forma que pode o Estado obrigar o cidadão a cumprir as leis, podem os indivíduos atuarem diante da iminência de abuso do poder.

Toda essa construção do Jusnaturalismo Moderno, que inverte o fundamento do poder do ex parte principis para ex parte populi, e que passa a depositar no indivíduo a verdadeira razão de ser do Estado e do direito, culmina na positivação Constitucional do direito de resistência à opressão pelas declarações da época revolucionária Francesa do século XVIII. O texto da declaração de Independência dos Estados Unidos de 1776 destaca que é um direito e dever do povo "alterar, abolir ou instituir um novo governo se ocorrerem abusos ou usurpações despóticas". No mesmo ano a declaração de Virgínia em seu artigo $3^{\circ}$ afirma que se o governo não garantir proteção e segurança ao povo, razão pela qual foi instituído, a sociedade terá contra ele um "direito inalienável de reformá-lo, alterá-lo ou aboli-lo de maneira considerada condizente com bem público.” (LUCAS, 1999, p. 32).

O direito de resistência é um nomen juris atribuído ao tiranicídio, a partir da construção de uma sociedade pautada pelo contratualismo, a racionalidade e a legalidade.

O discurso do tiranicídio (ou regicídio) também ingressou no debate político britânico moderno por meio de Thomas Hobbes (1588-1679), John Milton (16081674) e Stuart Mill (1806-1873). Mas terminou-se por adotar, na prática, a resistência institucionalizada e parlamentar, diferentemente dos meios revolucionários e violentos sucedidos na França e Holanda. (SAMPAIO, 2013, p.49).

Esse direito também é fruto de um poder constituinte que o legitima a resistir, pois esse "direito de desobedecer e de resistir que os muitos possuem resulta da primazia do sujeito constituinte sobre a ordem constituída. Porque o povo constitui seus governantes, ele tem o direito de resistir e de depô-los" (KALYVAS, 2013, p. 52). Assim, encontram-se na matriz constitutiva do Estado de Direito os requisitos que legitimam a resistência, bem como a sua institucionalização.

\subsection{Impeachment e a morte política}

O instituto do impeachment tem sua origem no direito britânico do século XIV. (BERGER, 1973). Nasceu lá, mas, por lá, não floresceu. Quase sempre se conta que "ele se desdobr[ou] do crepúsculo do século XIII, ou XIV, à madrugada do século XIX" (BROSSARD, 1992, p. 26) com a absolvição de Lord Melville em 1805, sendo esse o último impeachment ocorrido em terras britânicas. 
Quando de sua criação no seio britânico, correspondia à espécie criminal e monárquica que "desempenhou função estratégica na implantação do sistema de governo parlamentarista inglês" (RICCITELLI, 2006, p.04). A acusação então se iniciava na Câmara dos Comuns e, em seguida, era julgada pela Câmara dos Lordes que, por maioria simples, infligiam desde a pena de morte até o confisco de bens. O impeachment em sua formulação britânica servia para condenar tanto súditos quanto os representantes de altos cargos da Corte. (BROSSARD, 1992).

O impeachment, portanto, não tinha o condão de atingir o Rei, pois esse era fruto de uma emanação divina, ainda num Estado com constitucionalismo material à flor da pele e da história, não podendo ser destituído de seu poder monárquico. Apesar de que, "a acusação, na realidade, era ao monarca, entretanto, como este se posicionava acima dos homens e das coisas conforme a teoria do direito divino, não poderia ser atingido pelo instituto" (RICCITELLI, 2006, p.05).

Contudo, com o passar dos anos, no Reino Unido, o impeachment foi substituído pelo voto de confiança, visto que esse era mais compatível à sua realidade parlamentar, já que não exige a demonstração de irregularidades jurídicas cometidas pelo chefe de governo, bastando apenas que, por maioria simples, o Parlamento lhe confira desconfiança:

O impeachment se encaminhava para o museu das antiguidades constitucionais, na
medida em que novo estilo surgia nas relações entre os poderes, e para cujo advento
ele fora instrumento poderoso; relegada a ideia de sanção criminal como solução
ordinária de governo, o jogo da responsabilidade deixou de ser apurado através das
delongas de um processo judicial, passando a operar-se em termos de confiança
política. (BROSSARD, 1992, p. 30).

Apesar dessa substituição, o desenvolvimento do impeachment no seio inglês influenciou, em parte ${ }^{11}$, a sua adoção pelo direito norte-americano, que preferiu uma espécie política ou republicana "não sugerindo punições físicas ou patrimoniais, tornando-se procedimento de características essencialmente políticas" (RICCITELLI, 2006, p.04). Durante a Convenção da Filadélfia (1787), os pais fundadores demonstravam extensa preocupação em garantir ao recém-criado Estado mecanismos que pudessem afastar pretensões tirânicas, por meio do levante de representantes do Executivo que, em dado momento, pretendessem se

\footnotetext{
11 "Assim, ainda que o impeachment norte-americano derive de antecedentes britânicos, conforme a experiência das colônias e o modelo adotado pelos Estados - Bryce observa que ele resultou imediatamente das Constituições Estaduais e mediatamente do direito inglês -, embora conserve visíveis semelhanças com o instituto de origem, são nítidas as diferenças entre eles, a ponto de Pomeroy asseverar que 'o vocábulo foi tomado de empréstimo, imitado o procedimento, e nada mais; pois muito diferentes são o objeto e o fim dos processos'." (BROSSARD, 1992, p. 25).
} 
tornar reis com poderes ilimitados. Como acentuavam os federalistas, "tanto nesses Estados como na Grã-Bretanha, a prática do impeachment parece ter sido encarada como uma rédea com que o corpo legislativo pode controlar os servidores executivos do governo" (MADISON; HAMILTON; JAY, 1993, p. 418).

Motivados por seu histórico colonial de subjugação aos ditames da Metrópole e ansiando pela construção de um novo país, os constituintes, em 1787, dispuseram na Constituição americana a seguinte redação:

\section{Artigo I \\ [...] \\ Seção 2: [...]}

A Câmara dos Representantes elegerá o seu Presidente e demais membros da Mesa e exercerá, com exclusividade, o poder de indiciar por crime de responsabilidade (impeachment).

Seção 3: [...]

Só o Senado poderá julgar os crimes de responsabilidade (impeachment). Reunidos para esse fim, os Senadores prestarão juramento ou compromisso. O julgamento do Presidente dos Estados Unidos será presidido pelo Presidente da Suprema Corte. E nenhuma pessoa será condenada a não ser pelo voto de dois terços dos membros presentes. A pena nos crimes de responsabilidade não excederá a destituição da função e a incapacidade para exercer qualquer função pública, honorífica ou remunerada, nos Estados Unidos. O condenado estará sujeito, no entanto, a ser processado e julgado, de acordo com a lei. (ESTADOS UNIDOS, 1994, grifo nosso).

A partir desse momento, legitimou-se ao Legislativo a limitação das ações do Executivo, sempre que configurada a hipótese de crime de responsabilidade, sendo o instituto, portanto, recepcionado "como meio de controle do Parlamento aos funcionários da Administração tanto da divisão executiva como da divisão judicial”" ${ }^{12}$ (ACUÑA, 2012, p.03, tradução nossa).

O modelo adotado no Brasil, por sua vez, é bastante semelhante ao existente na Constituição norte-americana, com os requisitos de competência exclusiva da Câmara dos Deputados para "indiciar" por crime de responsabilidade; sendo competência exclusiva do Senado processar e julgar tais crimes. A condenação depende do voto mínimo de dois terços de deputados e senadores. Existe no ordenamento pátrio desde a Constituição Imperial de 1824, apesar de que, diante de seu Poder Moderador, o impeachment estabelecido nessa Constituição não atingia a pessoa do Imperador, punindo apenas os ministros de Estado.

Atualmente, o processo de impeachment presidencial é disciplinado no artigo 85, da Constituição de 1988, que prevê quais são os crimes de responsabilidade e, de forma

\footnotetext{
${ }^{12}$ Como medio de control del Parlamento a los funcionarios de la Administración tanto de la rama ejecutiva como la de la rama judicial.
} 
específica, a Lei 1079/50 que estabelece as normas de processo e julgamento. Desde a sua previsão pela Constituição Republicana de $1891^{13}$ até o presente momento, dois presidentes foram julgados em processos de impedimento: o ex-Presidente Fernando Collor de Mello, que, em 1992, renunciou ao mandato e a ex-Presidente Dilma Rousseff, que, em 2016, foi condenada pela prática de crimes de responsabilidade. O impeachment importa a perda do cargo e inabilitação para o exercício dos direitos políticos por oito anos.

Portanto, o que se pode observar é que, por meio deste instituto, a condenação ocorre mediante representação e a "morte" torna-se simbólica, pois visa atingir o "eu político", na medida daquilo que um Estado Constitucional passou legitimar.

\subsubsection{Recall}

A palavra recall de origem inglesa possui várias acepções semânticas desde a solicitação pela indústria para que seus consumidores devolvam alguns de seus produtos, que já estavam em suas posses, mas que, diante da constatação de determinado defeito de fábrica, precisam ser recolhidos e reparados pelo fabricante, até o recall político, acepção adotada nesse estudo, segundo a qual compete aos cidadãos a prerrogativa de destituir do cargo aquele agente público que não esteja atendendo aos requisitos que o cargo demanda. Em ambos os significados, o que se tem é a substituição daquilo que não está operando da forma como deveria ou se esperaria que funcionasse.

Esse instituto tem origem na legislação norte-americana, que parte do pressuposto de que ter um governo responsável está na fundação do sistema republicano e que, portanto, as razões para se retirar um representante do Estado a qualquer tempo e antes do período fixado de seu mandato devem advir de um pedido popular. (GILBERTSON, 1911, p.163).

Segundo William Bennet Munro (1946):

Diferente do impeachment, que é um procedimento semi judicial normalmente usado para livrar o governo de um agente culpado por ato criminoso, o recall é um instrumento político estruturado para assegurar uma responsabilização mais rigorosa ao eleitorado. Permite ao povo expulsar qualquer agente que falhar no cumprimento daquilo que lhe foi confiado. Tornando a responsabilidade pública contínua e direta. Por outro lado, o recall é uma arma que pode ser facilmente transformada em um uso indevido. Se utilizada com freqüência e sem a devida razão, poderia tornar o mandato público tão incerto quanto também impossibilitar que determinados

\footnotetext{
13 Será com a Constituição Republicana de 1891, que o instituto passará a prever a responsabilização do Presidente da República, pelos crimes de responsabilidade, por meio de seu artigo 53.
} 
homens e mulheres aceitem um cargo público ${ }^{14}$. (MUNRO, 1946, p. 672, tradução nossa).

O instituto do recall é, portanto, precipuamente político, pois coloca os agentes públicos “em bases políticas e a mercê de considerações políticas. De fato, é precisamente esta insegurança o elemento principal do recall. Ou, apenas, ter certa insegurança que é essencial para a capacidade de resposta que procura obter ${ }^{15 "}$ (GILBERTSON, 1911, p.165, tradução nossa). Contudo, diferentemente de um processo de impeachment, em que a decisão política emana dos representantes do povo admitidos, no caso do Brasil, nos cargos de deputados federais e senadores, com o recall, quem tem o poder de decidir quanto à destituição é o próprio povo.

Apesar da roupagem democrática e constitucional que os norte-americanos pretendem imprimir ao instituto do recall, a sua natureza essencialmente política, mesmo que operada pelo povo e a prerrogativa de destituição de cargo público sem fundamentações jurídicas e comprovação cabal dos motivos que levaram tal retirada do poder, aproximam-no, mesmo que brandamente, da prática tiranicida de outrora. Talvez a diferença seja apenas a manutenção da vida física do destituído.

\subsection{A internacionalização do tiranicídio}

Em uma dimensão internacional, por sua vez, o tiranicídio decorre da prática por Estados, denominados de civilizados, que pretendem, a partir de uma ação política legítima, “desestabilizar um sistema 'indiscutivelmente' opressivo (ou totalitário), para substituí-lo por um sistema legítimo, democrático, reconhecido a nível internacional16" (TURCHETTI, 2007, p.110, tradução nossa). Porém, dada à soberania e independência que cada Estado possui, nem sempre é permitido intervir politica ou até militarmente em uma soberania sem que, por meio dessa medida, acarretem-se severos conflitos de ordem interna ou internacional. Diante dessa

\footnotetext{
${ }^{14}$ Unlike impeachment, which is a semijudicial proceeding normally used to rid the government of an official guilty of criminal acts, the recall is a political instrument designed to secure stricter official accountability to the electorate. It enables the people to oust any officeholder who fails to fulfill his trust. It makes official responsibility continuous and direct. On the other hand, the recall is a weapon which may easily be turned to wrongful use. If resorted to frequently and without good reason, it could make official tenure so uncertain as to deter the right sort of men and women from accepting public office at all.

${ }^{15}$ But the recall frankly puts tenure of office on a political basis, at the mercy of political considerations. It is in fact this very insecurity of tenure which is the chief element in the recall. Or, rather, there is a certain insecurity that is essential to the responsiveness of action which the recall seeks to achieve.

16 Desestabilizar un sistema "indiscutiblemente" opresivo (o totalitario), para remplazarlo por un sistema legítimo, democrático, reconocido a nivel internacional.
} 
mpossibilidade, "é preciso recorrer a sanções substitutivas como o embargo, o bloqueio econômico ou outras, a fim de enfraquecer o sistema tirânico em questão ${ }^{17 "}$ (TURCHETTI, 2007, p.110, tradução nossa).

Essas são medidas usualmente utilizadas pelas nações "esclarecidas" e "civilizadas" para levar a democracia, liberdade e igualdade a países em que, acreditam, estejam sob o jugo de um governante ou um governo opressor, autoritário e violador de direitos fundamentais. A lógica é que essas medidas, desde as mais brandas como embargos econômicos até às mais extremas como invasão territorial, servem única e exclusivamente para trazer paz, estabilidade e progresso democrático ao país sob intervenção.

Contudo, Mario Turchetti (2007) alerta que:

Posto que, é extremamente problemático legitimar tal procedimento e garantir seu êxito (veja-se o caso "Saddam"), é indispensável promover preliminarmente um movimento de resistência no interior do país, por meio de uma propaganda adequada. Dito movimento deve permitir tomar, legitimamente, as rédeas do poder em substituição ao tirano destituído (ou seja do sistema desmantelado). Sem esta precaução, o tiranicídio pode se converter em uma tirania com consequiências imprevisíveis. Contudo, posto que todo ato tiranicida pode degenerar em um ato tirânico devem ser respeitados certos procedimentos, sobre tudo os que se referem ao direito humanitário, o projeto tiranicida se expõe a críticas, que podem chegar a inverter os termos do problema: aquele que a primeira vista era considerado libertador, pode logo ser considerado como novo opressor (os parâmetros de avaliação aqui fornecidos poderiam servir de base para dar outro enfoque a uma discussão sobre a intervenção no Iraque 2003: certos argumentos alertando sobre os perigos de uma ingerência militar não foram suficientemente examinados nesses debates). ${ }^{18}$ (TURCHETTI, 2007, p. 110, tradução nossa).

Há, nesses casos, portanto, a utilização, de um direito de resistência de terceiros, se é que isso existe, para legitimar a prática tiranicida. Violando abruptamente o ordenamento jurídico interno do Estado sob intervenção, além de acarretar implicações de ordem nacional e internacional, pois para considerar o dito tirano como tal, necessitam da aprovação das Nações Unidas e, com isso, colocam o Estado sob intervenção ao escrutínio de outros

17 Es preciso recurrir a sanciones sustitutivas como el embargo, el bloqueo económico o otras, con miras a debilitar el sistema tiránico en cuestión.

${ }^{18}$ Puesto que es extremadamente problemático legitimar tal procediemiento y garantizar su éxito (véase el caso “Saddam"), es indispensable promover preliminarmente un movimiento de resistencia en el interior del país, por medio de una propaganda adecuada. Dicho movimiento debe permitir tomar legítimamente las riendas del poder en reemplazo del tirano destituido (o sea del sistema desmantelado). Sin esta precaución, el tiranicidio se puede convertir en una tiranía con consecuencias imprevisibles. Ahora bien, puesto que todo acto tiranicida puede degenerar en un hecho tiránico de no ser respetados ciertos procedimientos, sobre todo los que atañen al derecho humanitario, el proyecto tiranicida se expone a críticas, que pueden llegar a invertir los términos del problema: aquel que a primera vista era considerado libertador, puede luego ser considerado como nuevo opresor (los parámetros de evaluación aquí brindados podrían servir de base para dar otro enfoque a una discusión sobre la intervención en Irak de 2003: ciertos argumentos alertando sobre los peligros de una injerencia militar no fueron suficientemente examinados en esos debates). 
Estados, que possuem uma tradição histórico-constitucional diversa da sua, gerando sem delongas guerras civis e embates entre potências mundiais.

O Tribunal Penal Internacional não escapa a estas constatações, criado em julho de 1998, durante a Conferência Diplomática de Plenipotenciários das Nações Unidas, ocorrida em Roma, constituiu-se como um tribunal, com sede em Haia, para ser, conforme seu artigo $1^{\mathrm{o}}$ "uma instituição permanente, com jurisdição sobre as pessoas responsáveis pelos crimes de maior gravidade com alcance internacional, de acordo com o presente Estatuto, e será complementar às jurisdições penais nacionais.”. (BRASIL, 2002).

Não se olvide que, antes da instituição pelo Estatuto de Roma, criaram-se os Tribunais de Nuremberg (1945) e de Tóquio (1945) e as figuras esquizofrênicas dos Tribunais ad hoc da antiga Iugoslávia (1993) e Ruanda (1994). Apesar de, majoritariamente, serem considerados um grande feito da Humanidade em direção à paz e à justiça, uma vez que permitiram a condenação de genocidas e criminosos de guerra, o que se tem, infelizmente, por detrás dessa fachada de defesa aos direitos humanos é a prática procedimentalizada, institucionalizada e internacional do tiranicídio de outrora. Evidenciando que, nada muda na história da Humanidade e, talvez, este seja o erro.

\section{CONSIDERAÇÕES FINAIS}

Da Antiguidade a dias atuais, o debate sobre a existência, pressupostos e a legitimidade do tirancídio persiste na esfera política e, mesmo que não se queira, desde a obra De Tyranno, de Bártolo de Sassoferrato ${ }^{19}$, esse debate vem transpondo a barreira política e atingindo a esfera jurídica, pois, nela precisa encontrar os fundamentos que o legitime. Já que, o que importa em toda essa discussão, não é apenas a existência milenar dessa prática ou da própria tirania em si, mas o fato de que ambas não representam nenhum bem. Destilam violência (física ou política) e colocam a vida em sociedade sempre em perigo.

\footnotetext{
${ }^{19}$ Bártolo de Sassoferrato nasceu em 1314 e se despontou como jurista italiano que, nos idos do século XIV elaborou a primeira obra medieval de caráter jurídico dedicada aos tiranos. De Tyranno, como foi denominado seu ensaio, composto por doze questionamentos ${ }^{19}$ serviu para ratificar a luta contra a tirania e obteve grande difusão entre os séculos XV e XVI, quando se tornou fonte primária contra a tirania instaurada na Florença republicana, governada de Coluccio Salutari a Savonarola. (KIRSHNER, 2006, p. 303-304).
} 
Sem embargo, mesmo com o sistema de separação de poderes e de defesa aos direitos fundamentais que estruturaram a organização social, a partir das Constituições, o que se tem, bem lá no fundo, onde ninguém deseja ver, é o ressurgimento, ou melhor, a modulação de uma doutrina antiga, mas, que agora, utiliza-se da sacrificabilidade da vida política como forma de expurgar aquilo que preceitua como indesejado. Se a Constituição não findou com a possibilidade do tirano, havendo mesmo os tiranos constitucionais, por imanência ou desfaçatez, ela, com sua lógica pacificadora, institucionalizou formas simbólicas de, se não matar, ao menos, afastar o tirano.

\section{Referências Bibliográficas}

AGAMBEN, Giorgio. Homo Sacer: o poder soberano e a vida nua. Tradução de Henrique Burigo. Belo Horizonte: UFMG, 2007.

ALBERTUS, Michael; MENALDO, Victor. Dealing with dictators: negotiated democratization and the fate of outgoing autocrats. International Studies Quarterly, v. 58, n. 3, p. 550-565, 2014.

ARENDT, Hannah. A condição humana. Tradução de Roberto Raposo. 12. ed. rev. Rio de Janeiro: Forense Universitária, 2014.

ARENDT, Hannah. Origens do totalitarismo. Tradução de Roberto Raposo. São Paulo: Companhia das Letras, 2007.

ARISTÓTELES. A Política. Tradução de Nestor Silveira Chaves. Rio de Janeiro: Ediouro. 1997.

BERGER, Raoul. Impeachment: the Constitucional problems. Cambridge, Massachusetts: Harvard University Press, 1973.

BIGNOTTO, Newton. "A tirania se aproxima de governos que se consolidaram por caminhos ilegítimos". Revice - Revista de Ciências do Estado. Belo Horizonte, vol. 1, n. 2, p. 233239, 2016. Disponível: < https://seer.ufmg.br/index.php/revice/article/view/3699>. Acesso em 24 mar. 2017.

BIGNOTTO, Newton. O silêncio do tirano. Revista USP, São Paulo, n. 37, p. 132-143, mar./maio, 1998. Disponível em: 〈http://www.revistas.usp.br/revusp/article/view/28343>. Acesso em: 23 mar. 2016.

BOURDIEU, Pierre. La force du droit [Eléments pour une sociologie du champ juridique]. Actes de la recherche en sciences sociales, v. 64, n. 1, p. 3-19, 1986. 
BRASIL, Decreto ${ }^{\circ}$ 4.388, de 25 de setembro de 2002. Promulga o Estatuto de Roma do Tribunal Penal Internacional. Disponível em:< http://www.planalto.gov.br/ccivil_03/decreto/2002/D4388.htm>. Acesso em: 09 abr. 2017.

BROSSARD, Paulo. O impeachment: aspectos da responsabilidade política do Presidente da República. 3. ed. São Paulo: Saraiva, 1992.

BROWN, Nathan. Constitutions in a Nonconstitutional World. Albany: Suny Press, 2002.

CAREY, John. Parchment, Equilibria, and Institutions. Comparative Political Studies, v. 33, n. 6, p. 735-761, 2000.

DERRIDA, Jacques. Force de loi: le "fondement mystique de l'autorité". Paris: Galilée, 1994.

DICE, Lee R. Man's Nature and Nature's Man: the ecology of human communities. Ann Arbor: University of Michigan Press, 1955.

ESTADOS UNIDOS. Constituição (1787). Constituição dos Estados Unidos da América ratificada em 21 de junho de 1788. Filadélfia, PA, Convenção da Filadélfia (1787). Tradução de J. Henry Phillips. Austin: Brazilian Translated, 1994. Disponível em:

<http://www.braziliantranslated.com/euacon01.html>. Acesso em: 15 jan. 2017.

FOUCAULT, Michel. História da sexualidade I: a vontade de saber. Tradução de Maria Thereza da Costa Albuquerque e J. A. Guilhon Albuquerque. 13. ed. Rio de Janeiro: Graal, 1999.

GEDDES, Barbara. Paradigms and Sand Castles. Ann Arbor: University of Michigan Press, 2003.

GILBERTSON, H.S. Popular control under the recall. The Annals of the American Academy of Political and Social Science, v. 38, issue 3, 1911. Disponível em:

<http://journals.sagepub.com/doi/abs/10.1177/000271621103800315>. Acesso em: 15 mar. 2017.

HUNTINGTON, Samuel P. Political development and political decay. World Politics, v. 17, n. 03 , p. 386-430, 1965.

HUNTINGTON, Samuel P. Political order in changing societies. New Haven: Yale University Press, 2006.

KALYVAS, Andreas. Democracia constituinte. Tradução de Florência Mendes Ferreira da Costa. Lua Nova: Revista de Cultura e Política. São Paulo, n. 89, p. 37-84, 2013.

Disponível em: <http://www.scielo.br/pdf/ln/n89/03.pdf>. Acesso em: 15 mar. 2017.

LOCKE, John. Segundo tratado sobre o governo civil. Tradução de Anoar Aiex. São Paulo: Abril Cultural, 1973. p. 37-139. (Os pensadores). 
LOEWENSTEIN, Karl. Teoría de la Constitución. 2a . ed. Barcelona: Ariel, 1976.

LUCAS, Doglas Cesar. Direito de resistência e desobediência civil: história e justificativas.

Revista Direito em Debate. v. 8, n. 13, 1999. Disponível em:

<https://www.revistas.unijui.edu.br/index.php/revistadireitoemdebate/article/view/807/525>.

Acesso em: 15 mar. 2017.

MADISON, James; HAMILTON, Alexander; JAY, John. Os artigos federalistas, 1787-

1788. Tradução de Maria Luiza X. de A. Borges. Rio de Janeiro: Nova Fronteira, 1993.

MAGALONI, Beatriz. Credible Power-Sharing and the Longevity of Authoritarian Rule.

Comparative Political Studies, v. 41, n. 4/5, p. 715-741, 2008.

MUNRO, William Bennet. The government of United States: national, state and local. 5. ed. New York: The MacMillan Company, 1946.

MYERSON, Roger. The Autocrat's Credibility Problem and Foundations of the Constitutional State. American Political Science Review, v. 102, p. 125-139, 2008.

POSNER, Daniel; YOUNG, Daniel. The Institutionalization of Political Power in Africa.

Journal of Democracy, v. 18, p. 126-140, 2007.

RICCITELLI, Antonio. Impeachment à brasileira: instrumento de controle parlamentar? São Paulo: Manole, 2016.

RUNCIMAN, Walter. The Social Animal. Ann Arbor: University of Michigan Press, 2000.

SAMPAIO, José Adércio Leite. Teoria da Constituição e dos Direitos Fundamentais. Belo Horizonte: Del Rey, 2013.

SARLET, Ingo Wolfgang; MARINONI, Luiz Guilherme; MTIDIERO, Daniel. Curso de Direito Constitucional. 5. ed. rev. e atual. 2016.

TOCQUEVILLE, Alexis. A democracia na América. Tradução de J.A. G. Albuquerque. São Paulo: Abril Cultural, 1973. p. 185-319. (Os pensadores).

TURCHETTI, Mario. ¿Por qué nos obstinamos en confundir despotismo y tiranía? Definamos el derecho de resistencia. Tradução de Victoria Espinosa Baquero. Revista de Estudios Políticos, n. 137, p. 67-111, 2007. Disponível em:

$<$ http://www.cepc.gob.es/Publicaciones/revistas/revistaselectronicas?IDR=3\&IDN=615\&IDA =26393>. Acesso em: 07 mar. 2017.

WEINGAST, Barry.The Political Foundations of Democracy and the Rule of Law. American Political Science Review, v. 91, n. 2, p. 245-263, 1997.

WRIGHT, Joseph. Do Authoritarian Institutions Constrain? How Legislatures Affect Economic Growth and Investment. American Journal of Political Science, v. 52, n. 2, p. 322-343, 2008. 